BOOK REVIEW

\title{
Neil Roughley and Kurt Bayerts (eds.): The Normative Animal? New York: Oxford University Press, 2019, $x+380$ pages
}

\author{
Jaroslav Peregrin*
}

Let me start this review in a personal tone. In a paper I wrote some ten years ago ('Rules as the Impetus of Cultural Evolution,' Topoi 33, 2014, 53145), I ventured the following thought:

There are many suggestions about what makes us humans special: soul, mind, language, culture, reason .... In this paper I have indicated that we may characterize man as a normative being. Not that this proposal by itself would be original - of course it goes back at least to Kant; and recently a persuasive case for it has, in effect, been made by Brandom. However, I have tried to show that if we accept the analyses of the concept of rule put forward by Sellars, we can embed this characterization in the evolutionary stories of how we humans have become what we are.

It was at that time that it came to me that the characterization of us humans as normative beings cuts surprisingly deep, firstly because many other of our specific abilities somehow depend on our normativity and, secondly, because this normativity is potentially explainable in a naturalistic manner. Hence my great excitement when I found that Oxford University Press have now published a volume called The Normative Animal?, as I assumed it would be devoted to this very idea. And indeed, one of the volume's editors, Neil Roughley, starts his introductory text as follows:

* Institute of Philosophy of the Czech Academy of Sciences \& Faculty of Philosophy, University of Hradec Králové

- Institute of Philosophy of the Czech Academy of Sciences, Jilska 1, 11000 Prague 1, Czech Republic; Faculty of Philosophy, University of Hradec Králové, Rokitanského 62, 50003 Hradec Králové, Czech Republic

$\triangle$ peregrin@flu.cas.cz

(C) The Author. Journal compilation (c) The Editorial Board, Organon F. 
Humans, it has often been claimed, are characteristically or even essentially rational, linguistic, social, or moral creatures. If these characterisations are intended to name the essence or nature of being human, however understood, then they would appear to be in conflict. This volume is built around the question of whether these characterisations may not turn out to be compatible because they all ground in a more basic feature: that of being creatures whose lives are structured at a fundamental level by their relationships to norms. The various capacities singled out by talk of rational, linguistic, social, or moral animals might then all essentially involve the orientation to obligations, permissions, and prohibitions. If this is so, then perhaps it is a basic susceptibility, or proclivity to the normative or deontic regulation of thought and behaviour that enables humans to develop the various traditionally emphasised features of their life form.

This, obviously, echoes my own musings about the import of normativity, so it fueled my keenness to see whether the papers assembled in the volume manage to put such musings on a more solid foundation. After reading the book, my impression is that they do in some partial areas, but that the question about the depth of the fundamental level (as referred to above in the introductory text) is not broached quite satisfactorily yet.

In the introductory essay which, together with a general introduction to the papers collected in the volume, constitutes the first part of the book, Neil Roughley provides a useful disambiguation of the concept of "normative creatures," namely as

(NA1) The creatures are beings to whom the norms apply.

(NA2) The creatures regulate their behaviour in line with what they take to be normatively required of them.

(NA3) The creatures are in some sense creators and upholders of the norms.

(NA4) The creatures are enforcers of the norms.

He himself considers (NA2) as crucial. (Here, I must admit, I disagree: personally, I would go for (NA3), which, in my view, involves (NA4). If one opts for either (NA1) or (NA2) as crucial, then a separate explanation is needed to account for how the norms we humans obey ever came into being.) Roughley also discusses the three kinds of norms to which the ensuing book parts are devoted: social norms, moral norms, and linguistic norms. 
Of the papers in the next part, devoted to social norms, the last is the one I find the most interesting. It is written by two prominent members of the former Leipzig group around Michael Tomasello, namely Marco Schmidt and Hannes Rakoczy, who have been studying the ontogenesis of normativity for over a decade. In their current contribution ('On the Uniqueness of Human Normative Attitudes'), they summarize the results of their experiments with children and draw some important conclusions. The concept they focus on is that of having a normative attitude: the tendency to divert fellow beings either away or toward various courses of action. It is the awakening of these attitudes that the authors claim marks the early ontogenesis of us humans and makes us the normative beings we are. I think this empirical approach to normativity has a dual significance: on the one hand, normative attitudes can be seen as constitutive of implicit rules which, in turn, can be seen as underlying all rules; while also, on the other hand, they can be seen as something explainable in purely naturalistic terms.

Another interesting paper in this part is the first contribution by Peter M. Kappeler, Claudia Fichtel, and Carel P. van Schaik ('There Ought to Be Roots: Evolutionary Precursors of Social Norms and Conventions in Non-Human Primates'). These authors, too, stress the importance of normative attitudes (though they do not call them so): they suggest that normativity consists in the expectations of individuals in respect to the courses of actions of others, and claim that such expectations can be diagnosed only in terms of the perceivable reactions of the individuals to the violations of such expectations. The authors also try to identify the pre-normative components out of which our normativity has been assembled; which they see especially in dyadic interactions.

This part of the book also gives us contributions from two other authors, Christoph Antweiler ('On the Human Addiction to Norms') and Karl Mertens ('On the Identification and Analysis of Social Norms and the Heuristic Relevance of Deviant Behaviour'), who address normativity and its role within human communities mostly from the viewpoint of philosophy and cultural anthropology.

The third part of the book, devoted to moral norms, cannot fail to reflect the ongoing discussion concerning the question whether moral norms constitute a specific kind of norm or whether they are merely a loosely delimited "core" of social norms. That moral norms are sui generis is defended by this part's introductory paper, 'The Evolution of Human Normativity: The Role of Prosociality and Reputation Management' by Carel P. van Schaik and Judith M. Burkart. 
The authors argue that moral norms are the only genuine norms, the existence of which was necessitated by the organization of the communities of our ancestors, all other norms then arising as their relaxed variants. Karl Bayertz, in the next contribution ('The emergence of moral normativity'), defends the opposite standpoint: according to him, moral norms have developed out of the more broadly social ones especially in connection with the onset of language. Something similar is claimed also by the author of the following paper ('Joint Activities and Moral Obligation'), Holmer Steinfath, who, likewise, stresses the role of language within the emergence of moral norms out of the social ones. He is convinced that the importance of language consists especially in that it allows us to produce justifications. The last two chapters of this part of the book ('The Development of Domains of Moral and Conventional Norms, Coordination in Decision-Making, and the Implications of Social Opposition' by Elliot Turiel and Audun Dahl, and 'Moral Obligation from the Outside In' by Neil Roughley), argue that social and moral rules are quite different species, neither of them being an outgrowth of the other.

The fourth and last part of the volume, devoted to linguistic rules, starts with a contribution by Nicola Kompa ('Language evolution and linguistic norms'), who argues that it is rules that make it possible to turn signals into symbols (to allow them to acquire a conventional meaning that is stable) and in this sense they underlie language. A similar picture is drawn by N. J. Enfield and Jack Sidnell ('The normative nature of language'), who also use the Peircean conceptual framework. They claim that "whenever a word is used, that word will dependably invoke a definable core idea in the minds of people who hear the word being used" and insist that "the norm-governed flow of sequences of social interaction provides a matrix in which norms of language are used for regimenting the use of language, and thereby concretizing these norms in the form of semantic conventions." Anne Reboul ('Can there be linguistic norms?'), in contrast to this, rejects normativity as a substantial ingredient of language. In the last paper of this part of the book, Hanjo Glock's 'The normativity of meaning revisited,' the author reviews and elaborates on some philosophical arguments, going back to Wittgenstein, for the normativity of meaning.

The question whether we humans are normative animals can be construed in various, weaker and stronger, senses. In the weakest sense, the question asks whether we are able, perhaps in contrast to other animals, to abide by norms; and needless to say that to this the answer is positive. In a stronger sense, the question asks whether normativity is a ubiquitous feature of human life form. 
Here the book brings forth a lot of evidence for the positive answer to this question, while also presenting us with some dissenting voices, which force the "normativists" to refine their positions. Importantly, though, I would hold that this question can be asked in a yet stronger sense, asking whether rules are our principal distinction, underlying all other specifica of us humans, such as reason, language, cognition, morality etc. Personally, I believe that even here the answer may be positive, and I find it fascinating to probe this topic. (It is not just a lunatic idea: inferentialism has come up with an elaborated theory regarding language and linguistic meaning, according to which meaning is a matter utterly of rules, and hence that language is underlain by rules; and views that our specifically human cognition is derived from language are no longer counted as extreme.) In this respect I think the book does not go far enough (though, we saw, one of the editors in his introduction, does interpret the question in this strong sense), perhaps because most of the authors do not think that the strong sense of the question is worth being taken seriously. 